\title{
COLOUR QUALITY TESTING OF CYAN OFFSET PRINTS DEPENDING ON PIGMENT CONCENTRATION AND DIFFERENT CTP SCREENING MODE
}

\author{
Sandra Mustač, Igor Majnarić (iD), Stanko Bauk, Slaven Miloš \\ University of Zagreb, Faculty of Graphic Arts, Zagreb, Croatia
}

\begin{abstract}
One of the problems in the offset printing technique is the picking of uncoated paper, which occurs due to the activity of pressure cylinder and sticky offset inks. To reduce offset ink stickiness, it is possible to add cheaper ink filler that will indirectly reduce the concentration of pigment. However, there is also a reduction in the colour tones and quality of reproduction. In this experiment we used: standard cyan offset ink (Sun Lit Express ink which consists of phthalocyanine based pigment) and high-quality gloss coated cardboard ( $250 \mathrm{~g} / \mathrm{m} 2$ Euroart plus gloss). This paper aims to show how the CTP screening type (AM/FM mode) and the CTP line screening (80, 100, 120 line/ $\mathrm{cm}$ and $10 \mu \mathrm{m}, 20 \mu \mathrm{m} 25 \mu \mathrm{m}$ diameter of print elements) manifest on the reproduction quality of a standard gradation wedge. This research will create the possibility of correlating the factors of user reduction of pigment concentration and reproduction quality of cyan colour separation. By using the AM screenings and adding different concentrations of ink filler, more stable cyan prints are achieved.
\end{abstract}

Key words: Offset printing, Cyan offset ink, filler additive, AM and FM CTP screening

\section{INTRODUCTION}

\subsection{Offset printing technology}

Offset or lithographic printing is the most common printing technique because offset printing can print a wide range of products. The technique is popular for large print-run products such as magazines, posters, flyers, packaging, brochures, business cards, etc. The great advantage of offset printing is the quality of prints with low product cost, quick and easy preparation (Majnarić, 2004). Unlike gravure and letterpress techniques, the offset technique is specific because of the printing form relief (printing and nonprinting elements be in almost the same plane). The difference between the two surfaces is in their different physical-chemical properties.

\subsection{Offset printing inks}

The offset printing technique uses very specific and complex ink composition. The reason for this complexity is the fact that during printing the ink must meet many different conditions (ink must be transferred to the printing elements on the form, then to the offset cylinder, and finally to the printing substrate). Offset ink must be extremely viscous, have specific tack, good dispersion, and must not be prone to emulsification and toning. Their dynamic viscosity does not exceed the limits of 40 to $100 \mathrm{~Pa}$ s. Imprints obtained by offset technique are considered high quality, and it is possible to reproduce even the finest details. In its composition, the offset ink contains a binder, pigment, and various additives. The filler is one of the possible additives. The amount of filler in the ink will have a direct impact on the transfer and price of the ink, as well as on the print quality. Therefore, it is very important to prepare the ink well before use. Due to the good coverage of the printing elements, the offset ink must have a higher amount of pigment (for better moisture resistance). Offset ink must be made from pigments of high tone hue and higher concentration.

Also, offset ink must not destroy the offset rubber and cause it to swell. The ink should not be diluted too much, as poor paper acceptance may occur. On the other hand, it is known that the pigments in the lithographic offset ink must emulsify to achieve a good water-ink balance. Pigments are the most expensive ink component (Christie, 2001). To reduce the price and stickiness, a cheaper filler is added to the ink, which reduces the concentration of pigment. With such a change, it is still possible to get a quality print. 


\subsection{Pigment for cyan ink}

The pigment is one of the main components of the ink. The most important property of pigments is that it determines the exact tone of the ink. The pigments must be insoluble in the binder, but they must be well dispersed and well wetted. Process ink (cyan, magenta, yellow and black) with synthetic pigments have satisfactory properties and ensure good transfer from the printing form to the offset blanket and printing substrate (Thompson, 2004).

The cyan pigment reflects $2 / 3$ of the visible spectrum (absorbs the red part of the spectrum well, and reflects the blue and green part of the spectrum). The cyan ink most commonly used today is based on a pigment built from phthalocyanine. It is also the only substance capable of achieving a satisfactory colour tone value. Cyan ink contains phthalocyanine pigment of molecular formula $\mathrm{C}_{32} \mathrm{H}_{18} \mathrm{~N}_{8}$, which is mostly used today as a pigment for inks, coatings, and colouring plastics. Phthalocyanine was discovered as a pigment in 1907 when Swiss scientists accidentally synthesized it and characterized it as extremely stable. Patrick Linstead, in 1928, defined and characterized phthalocyanine as a good pigment for ink (Turinski, 1970). Today's phthalocyanine-based cyan ink include two variations: copper-phthalocyanine blue (Copper Phthalocyanine Blue) and copper polychlorophthalocyanine green (Copper Polychlorophthalocyanine Green) (Leach and Pierce, 1993).
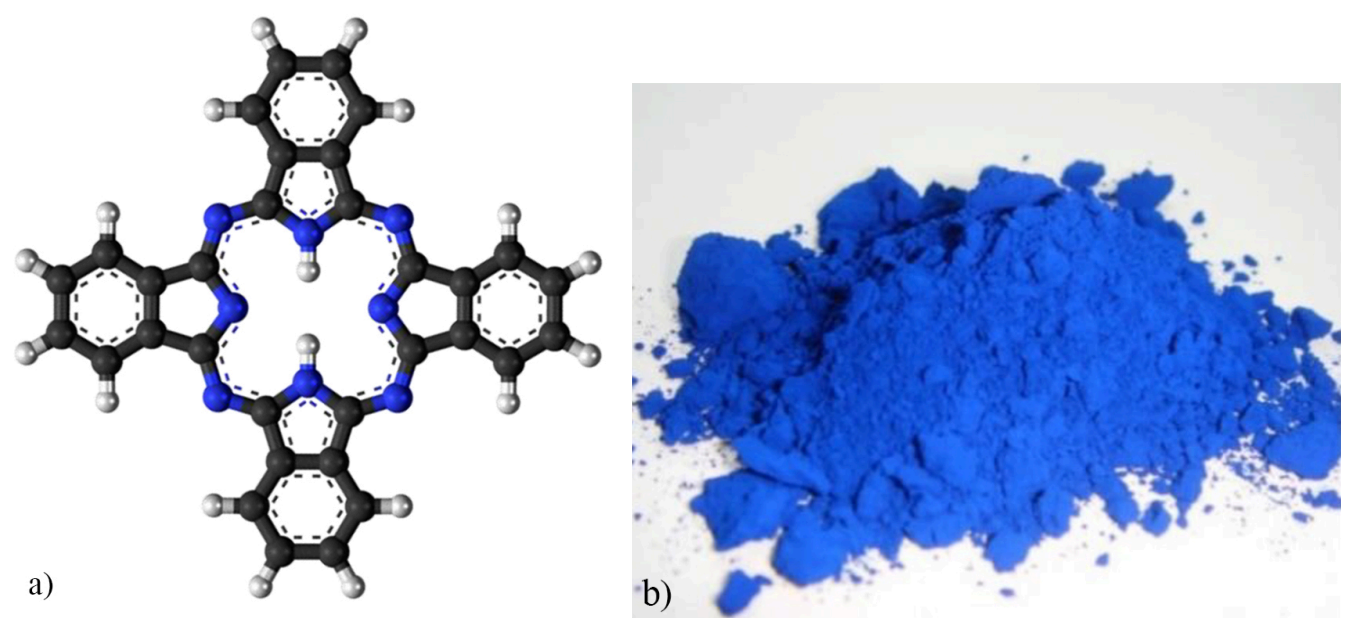

Figure 1: Blue 15 pigment: a) chemical structure b) visual appearance

Cyan pigment is insoluble in water and resistant to acids and alkalis. Due to their exceptional resistance to air, light, and water, they have found a very wide application. As shown in figure 7 Phthalocyanine pigments are most commonly blue and green hue and consist of multiple rings including 4 benzene rings and 8 nitrogen atoms attached to copper. They are thermally very stable and insoluble but can sublimate over time. Sublimation occurs at a temperature higher than $500^{\circ} \mathrm{C}$. Pigments absorb light well between 600 and $700 \mathrm{~nm}$, and such material has a blue or green colour tone. Copper phthalocyanine will be formed if phthalonitrile is heated with divalent copper salts (Figure 8). The compounds thus formed are very stable and can form substituted benzene derivatives by heating in the presence of nitrogen and metal salts. Ecologically, the copper phthalocyanine compound is not toxic to fish and plants, but it is not biodegradable. The pigment is not carcinogenic on short-term exposure.

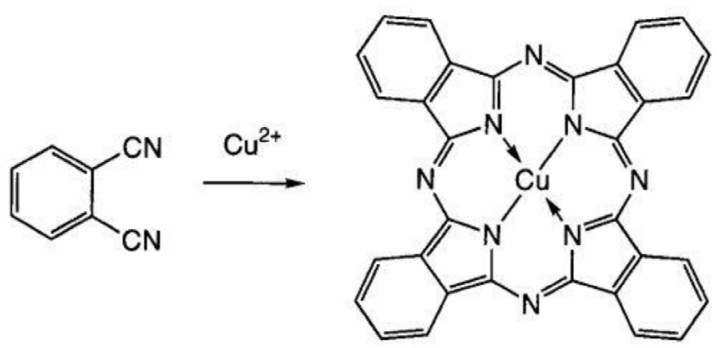

Figure 2: Synthesis of phthalocyanine. 


\subsection{Binders}

Binder is the second most important component in printing ink. It serves to bind and disperse the pigment particles into one unit. Binders give the ink good chemical and physical properties and ensure good quality of transfer to the substrate. The binder can be a viscous liquid (various oils) or a resinous solution (obtained by dissolving a solid resin in an organic solvent or oil). They do not contain many VOC = Volatile Organic Compound (unpleasant odor and harmful to the environment and people). Solvents by chemical structure can be ketones (acetone), esters (various acetates), alcohols (isopropyl alcohol), and hydrocarbons (toluene, xylene, oil) (Majnarić, 2004). The binder of offset ink is based on linseed oil and artificial resins, and mineral oil is used as a solvent (Vančina and Mikota, 1993). Drying is relatively fast, and time is essential for the final drying of the ink after printing.

Linseed oil is vegetable oil and is obtained by pressing or extracting flax seeds. It belongs to the category of semi-dry binders. Drying takes three to six days and can be accelerated by adding dry agents. When drying on the surface of the print, such ink creates a thin layer of film. Resins occupy a very important place in the production of offset graphic inks and varnishes. They give the ink specific properties: strength, gloss, adhesion, flexibility, resistance to higher temperatures, resistance to acids, resistance to alkalis, faster drying. Resins are VOC and can be viscous liquids or amorphous solids of relatively large molecular weight. They are insoluble in water and soluble in some organic solvents.

\subsection{Fillers}

Fillers or auxiliary pigments are solids and can be of natural or artificial origin. They are an important component of ink because they replace the more expensive pigment. Excessive concentration of pigments in the ink, also, has a higher price, and a negative effect on printing properties. Their role is to replace pigments as well as possible, but without affecting the original tone of the ink. By reducing the concentration of pigments, there is a reduced intensity of printed colours. In composition may be white or transparent inorganic powders. Today's mineral fillers or more expensive artificial fillers are used.

Artificial fillers are white fine-grained powders formed by the sedimentation of sparingly soluble salts. Artificial fillers have lower hardness but also higher dispersion. Therefore, their use is greater. Fillers must not chemically react with the binder and dissolve in it. Fillers are insoluble in water and are well dispersed and wettable. Aqueous dispersion fillers are visually opaque, and oil dispersion fillers are only partially transparent. Fillers have a difference in chemical composition and fineness of particles. The particle size can be chemically affected, which adapts to the binder (it will affect its wetting). The refractive index of the filler ranges is between 1,45 and 1,65 . When choosing a filler, its refractive index must be as close as possible to the refractive index of printing binders (near 1,48). The specific gravity of the filler is between 1,5 and $4,5 \mathrm{~g} / \mathrm{cm}^{3}$ (Jamnicki, 2013a). Fillers used to replace pigments in the printing ink are shown in Figure 3.

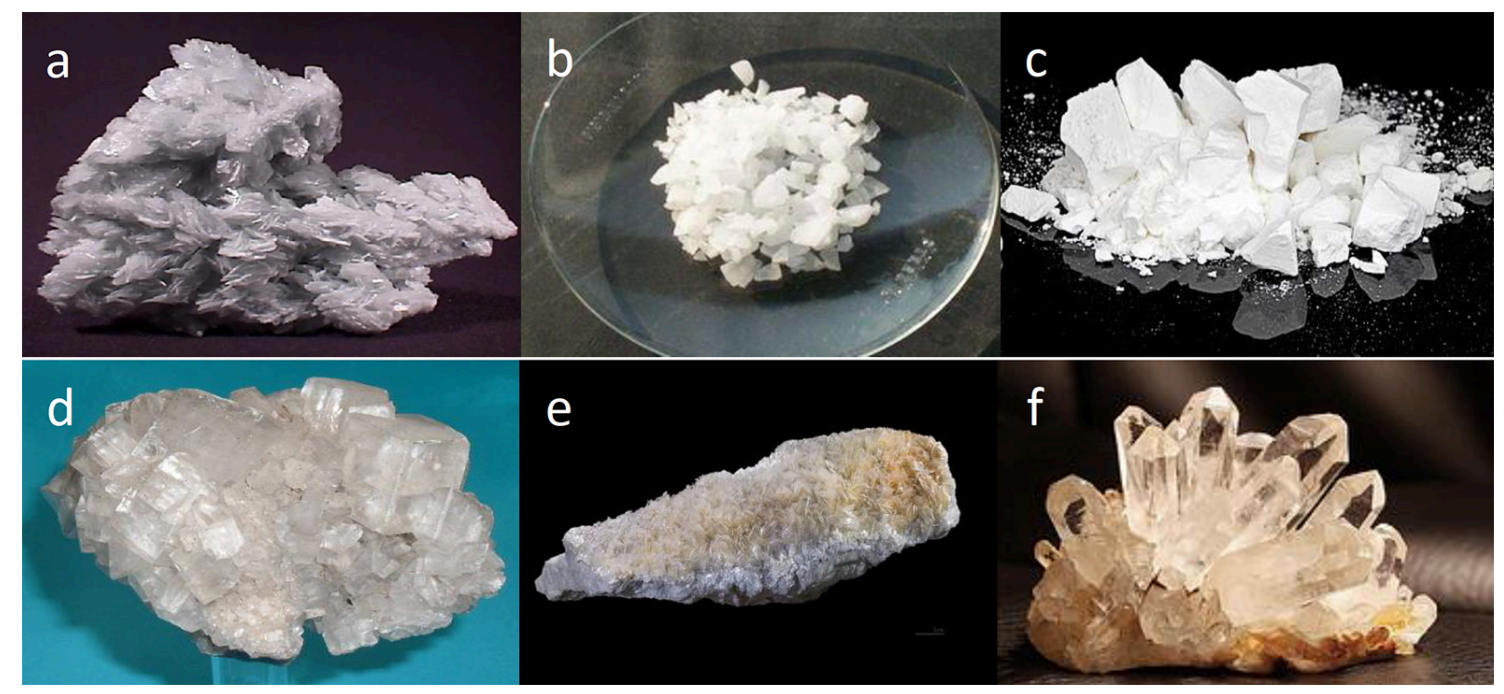

Figure 3: Typical fillers in offset inks: a) barium sulfate - $\mathrm{BaSO}_{4}$, b) aluminum hydroxide - $\left.\mathrm{Al}(\mathrm{OH})_{3}, \mathrm{c}\right)$ magnesium carbonate $-\mathrm{MgCO}_{3}$, d) calcium carbonate $-\mathrm{CaCO}_{3}$, e) talc $-\mathrm{Mg}_{3} \mathrm{Si}_{4} \mathrm{O}_{10}(\mathrm{OH})_{2}$, f) silicon dioxide $\mathrm{SiO}_{2}$ 


\subsection{Additives}

For good printability offset inks contain various additives such as microorganism control agents, wetting agents, antioxidants, scents. They improve certain colour properties or eliminate unwanted appearances on the printing process. Depending on the problems in printing, the printing additives can be solved: poor ink drying, high ink stickiness, printing error concerning the appearance on the printing form, incorrectly printed surface, rubbering of paper, colour remaining on the offset blanket, etc.

Dryers or siccatives are substances that are added to printing ink to improve the time of dryings. The dryers are added to the ink afterward by adding them directly to the printing press. They must be added carefully because due to the high concentration of the same ink in the printing process may begin to dry prematurely. Metals salts that contain lead, manganese, and cobalt are used as driers. The offset printing technique usually uses concentrated or oily driers made from concentrated solutions of linoleate, resin, or borate of lead and manganese, dissolved in linseed or some other suitable oil with or without the addition of synthetic resins or rosin (Jamnicki, 2013b). This paper aims to determine the quality of cyan offset prints and if is possible to reduce the concentration of pigments without losing the basic function of the offset inks (appearance of the appropriate colour tone on the print). It can be assumed how to affect the changes in the colour properties of the print with different screenings settings.

\section{EXPERIMENTAL}

The paper will examine the quality of cyan prints depending on the filler content. Euroart plus gloss coated paper $(250 \mathrm{~g} / \mathrm{m} 2)$ was used as the printing substrate. Before printing, test patches were created using the Kodak Prinenergy EVO workflow (enables control of the preparation process). Each part of the patch was treated separately by determining the type and shape of the raster elements, the line screening, or the fineness of the raster. As a result, all samples were on only one printing sample (AM raster with three different 80, 100, and $150 \mathrm{lin} / \mathrm{cm}$ lines and FM raster with 10, 20, and 25 microns).

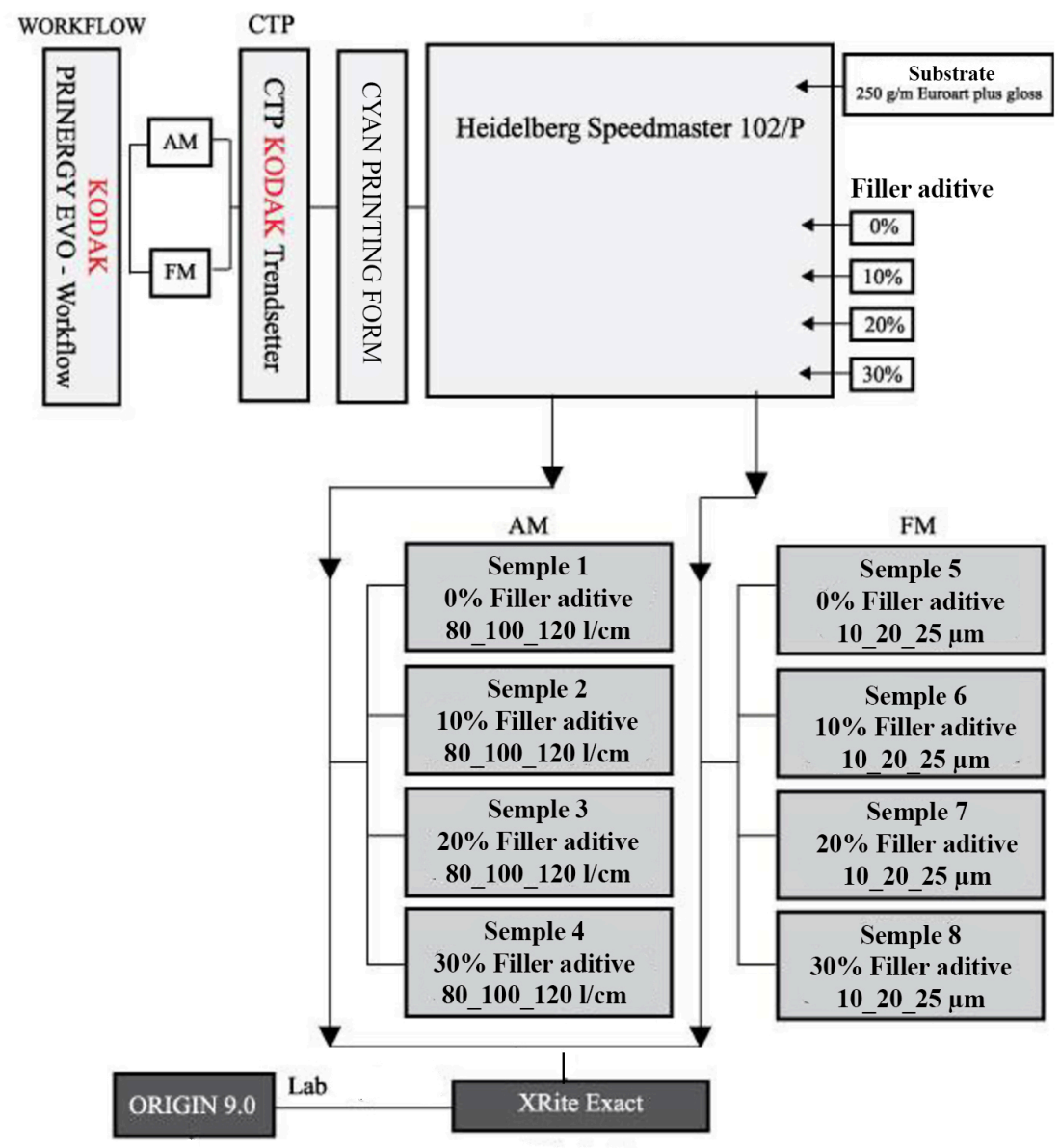

Figure 4: Schematic representation of the performed experiment 
After screening, the printing form was generated on a CTP Kodak Trendsetter. Before each printing, the inks were changed in the machine, which difference in the percentage of additional filler. This meant that the machine had to be cleaned and re-prepared for printing after each print (four times in total). Four mixtures of cyan inks were used: cyan ink with $0 \%$ added filler, cyan ink with $10 \%$ added filler, cyan ink with $20 \%$ added filler, and cyan ink with $30 \%$ added filler. All samples were printed on a two-colour offset machine Heidelberg Speedmaster 102/P with a hard offset rubber blanket. The impression cylinders were dimension B2 and samples were cut into 8 pieces for the work. All samples were measured with an X-rite Exact colorimeter and spectrophotometer. After all tests, the obtained $L^{*}, a^{*}$, and $b^{*}$ coordinate values were processed in the ORIGIN 9.0 program (Figure 4).

\section{RESULTS AND DISCUSSION}

After the experiment, all samples were subjected to colorimetric testing. Using X-rite Exact, 5 measurements of each sample were performed (with activation of the DE calculation mode and automatic display of the measured mean value). From the obtained $L^{*}, a^{*}, b^{*}$ coordinate values, the colour difference was calculated between prints without filler additives and prints with $10 \% 20 \%$, and 30\% added filler. Based on DE 2000 formula in Origin 9.0, was made 3D graphs of the colour difference depending on the filler addition. A separate graph of colour difference was made for each type of screening. The colour deviation of the cyan fields of $20 \%, 40 \%, 60 \%, 80 \%$, and $100 \%$ TV generated during the experiment is shown in Figure 5 and Figure 6.
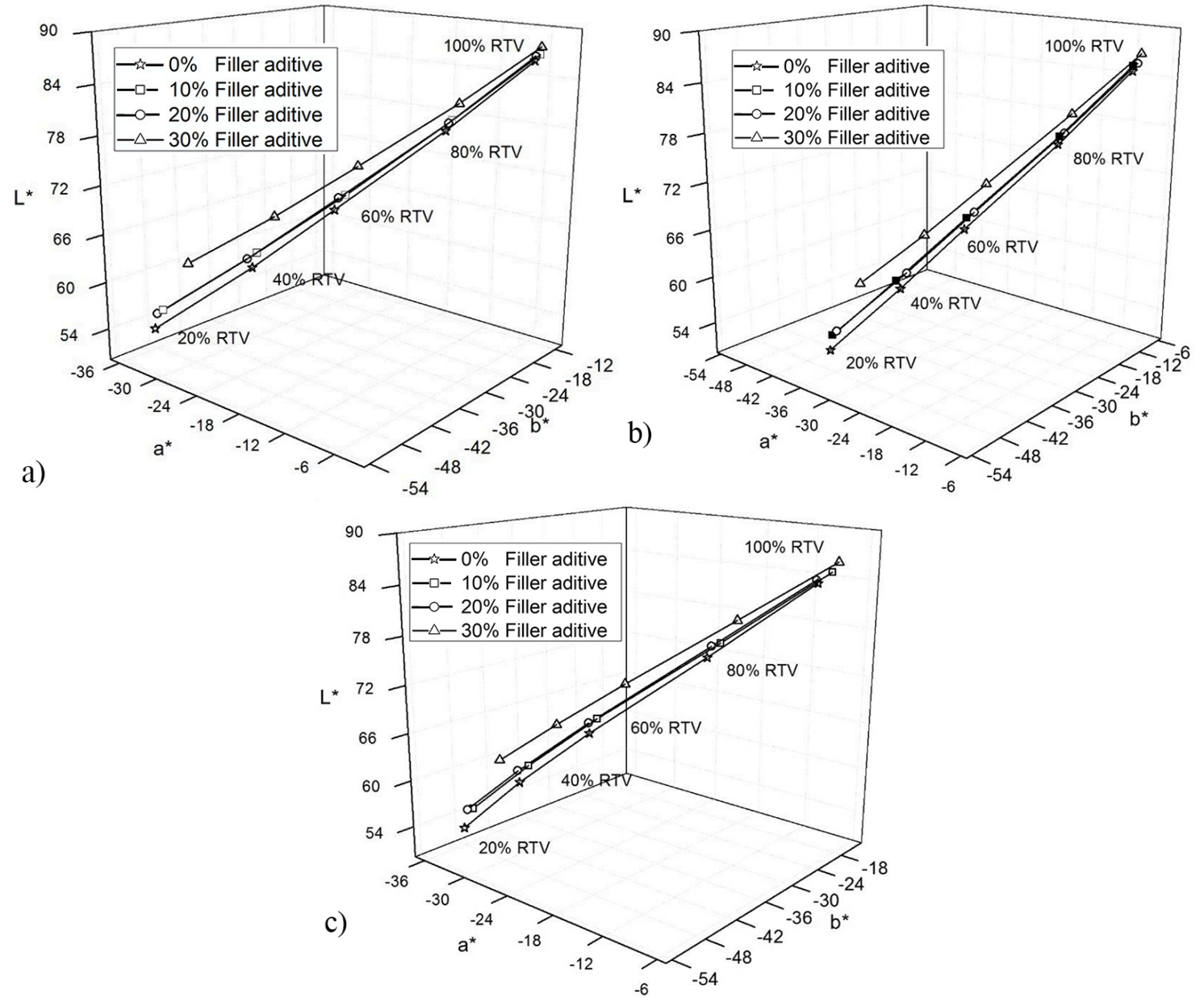

Figure 5: Colour change of cyan tones from for FM raster: a) $25 \mu \mathrm{m}$; b) $20 \mu \mathrm{m}$ and c) $10 \mu \mathrm{m}$.

In the printing industry, FM screening is enabled by the use of powerful computers whose algorithm achieves different tonal value with the application of the same dimensions of the least printing elements (raster dots). In all three FM cyan prints, the full tone is stable, which is achieved by printing all screenings at once. 
The deviation of the full tone was thus achieved only by the addition of ink filler, which led to a reduction in the concentration of pigments in the printed layer. This is particularly pronounced in the brightness and colour change of $\mathrm{DE}=5$.

The addition of $10 \%$ ink filler in a screening with larger raster elements achieves slightly larger colour changes in cyan tones. They are visually visible in dark areas $\left(D E_{00}>1\right)$. Reducing the raster dot sizes of cyan prints was stabilizes and reduces the cyan colour deviation value.

With a larger addition of filler ( $20 \%$ and $30 \%$ mass weight), colour changes are more pronounced (visible to the human eye). Such a trend was observed in all analyzed tonal areas and especially in darker tones where colour differences are greater than DE60\% TV_80\% TV>5. The reason for this a movement of the results is manifested in the increase of the dot gain in the finer FM screening, which leads to an increase in the surface coverage of the same tones (Table 1).

Table 1: Colour changes caused by cyan prints realized with FM screenings

\begin{tabular}{|c|c|c|c|c|c|}
\hline \multirow{2}{*}{$\mathrm{FM} 25 \mu \mathrm{m}$} & \multicolumn{5}{|c|}{ Cyan Colour difference CIE LAB DE2000 } \\
\hline & $20 \% \mathrm{TV}$ & $40 \% \mathrm{TV}$ & $60 \% \mathrm{TV}$ & $80 \% \mathrm{TV}$ & $100 \% \mathrm{TV}$ \\
\hline $\begin{array}{c}0 \% \_10 \% \\
\text { Filler_aditive }\end{array}$ & 0,75 & 0,89 & 1,24 & 1,25 & 1,53 \\
\hline $\begin{array}{c}0 \% \_20 \% \\
\text { Filler_aditive }\end{array}$ & 0,94 & 1,45 & 1,62 & 1,78 & 2,15 \\
\hline $\begin{array}{c}0 \% \_30 \% \\
\text { Filler_aditive }\end{array}$ & 2,00 & 3,07 & 4,66 & 5,42 & 6,43 \\
\hline \multirow{2}{*}{$\mathrm{FM} 20 \mu \mathrm{m}$} & \multicolumn{5}{|c|}{ Cyan Colour difference CIE LAB DE2000 } \\
\hline & $20 \% \mathrm{TV}$ & $40 \% \mathrm{TV}$ & $60 \% \mathrm{TV}$ & $80 \%$ TV & $100 \%$ TV \\
\hline $\begin{array}{c}0 \% \_10 \% \\
\text { Filler_aditive }\end{array}$ & 0,77 & 0,64 & 0,73 & 1,23 & 1,49 \\
\hline $\begin{array}{c}0 \% \_20 \% \\
\text { Filler_aditive }\end{array}$ & 1,38 & 1,59 & 1,79 & 2,14 & 2,19 \\
\hline $\begin{array}{c}0 \% \_30 \% \\
\text { Filler_aditive } \\
\end{array}$ & 2,45 & 3,96 & 4,98 & 5,72 & 6,33 \\
\hline \multirow{2}{*}{$\mathrm{FM} 10 \mu \mathrm{m}$} & \multicolumn{5}{|c|}{ Cyan Colour difference CIE LAB DE2000 } \\
\hline & $20 \%$ TV & $40 \% \mathrm{TV}$ & $60 \% \mathrm{TV}$ & $80 \%$ TV & $100 \% \mathrm{TV}$ \\
\hline $\begin{array}{c}0 \% \_10 \% \\
\text { Filler_aditive }\end{array}$ & 0,54 & 0,52 & 1,01 & 1,09 & 1,86 \\
\hline $\begin{array}{c}0 \% \_20 \% \\
\text { Filler_aditive } \\
\end{array}$ & 0,94 & 1,55 & 2,14 & 2,07 & 1,95 \\
\hline $\begin{array}{c}0 \% \_30 \% \\
\text { Filler_aditive }\end{array}$ & 2,60 & 3,88 & 5,28 & 5,59 & 6,23 \\
\hline
\end{tabular}

Opposite to FM, old amplitude-modulate screenings are often used in print. They have different surface coverage achieved by increasing the raster elements. For this test, a line screening sample is used, which is characterized by a high frequency of raster elements (80, 100, and 120 lpc). In the performed experiment, the colour deviations of the full tones are identical to the FM screening. This is a direct result of different filler concentrations. In all three cyan AM prints, the full tone is stable and achieves an overall colour change around DE 5 .

The addition of $10 \%$ ink filler in screenings with a smaller lineage achieves the least colour changes in cyan tones. They are visually invisible. Increasing the line screening in AM rasters does not lead to major changes in cyan tone values.

With a larger addition of fillers (20\% and 30\%), colour changes become more pronounced and visible to the human eye. Such a trend was observed in all analyzed tonal areas, especially in darker tones (colour differences greater than DE80\% TV>5). By reducing the size of the raster elements and cyan pigment concentration, a colour change is achieved (deviation tone value is about DE 1). Dot gain of a finer AM screening thereby reducing the surface coverage of such tones (Table 2). 

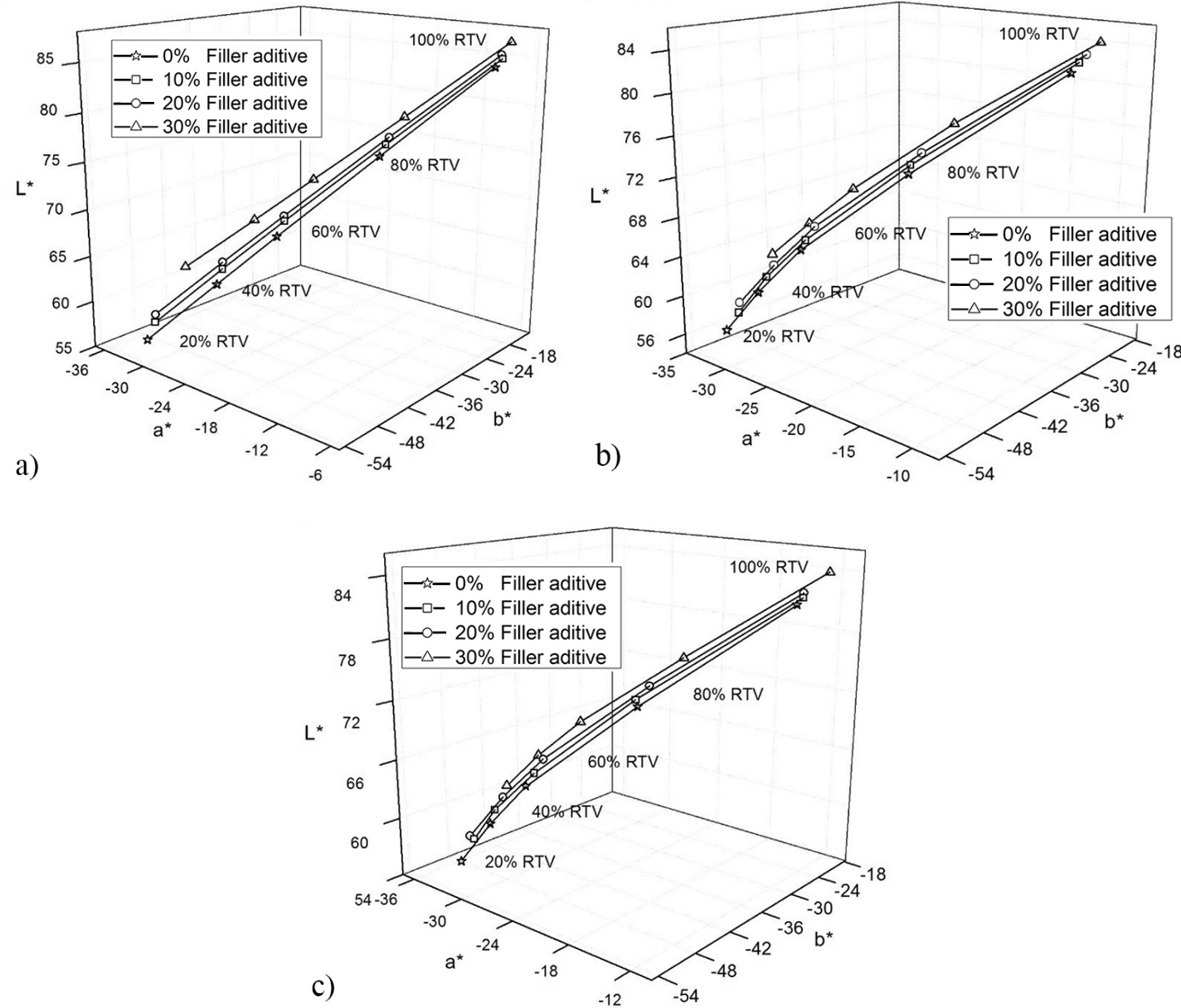

Figure 6: Colour change of cyan tones from for AM raster: a) 80 Ipc; b) 100 lpc and c) 120 lpc.

Table 2 Colour changes caused by cyan prints realized with AM screenings

\begin{tabular}{|c|c|c|c|c|c|}
\hline \multirow{2}{*}{ AM 80 Ipc } & \multicolumn{5}{|c|}{ Cyan Colour difference CIE LAB DE2000 } \\
\hline & $20 \%$ TV & $40 \%$ TV & $60 \%$ TV & $80 \%$ TV & $100 \%$ TV \\
\hline $\begin{array}{c}0 \% \text { } 10 \% \\
\text { Filler_aditive }\end{array}$ & 0,41 & 0,65 & 1,03 & 0,82 & 1,36 \\
\hline $\begin{array}{c}0 \% \_20 \% \\
\text { Filler_aditive }\end{array}$ & 0,61 & 0,90 & 1,37 & 1,32 & 1,85 \\
\hline $\begin{array}{c}0 \% \_30 \% \\
\text { Filler_aditive }\end{array}$ & 1,24 & 2,33 & 3,87 & 4,62 & 6,45 \\
\hline \multirow{2}{*}{ AM $100 \mathrm{lpc}$} & \multicolumn{5}{|c|}{ Cyan Colour difference CIE LAB DE2000 } \\
\hline & $20 \%$ TV & $40 \% \mathrm{TV}$ & $60 \% \mathrm{TV}$ & $80 \% \mathrm{TV}$ & $100 \% \mathrm{TV}$ \\
\hline $\begin{array}{c}0 \% \_10 \% \\
\text { Filler_aditive }\end{array}$ & 0,46 & 0,69 & 1,01 & 0,84 & 1,39 \\
\hline $\begin{array}{c}0 \% \_20 \% \\
\text { Filler_aditive }\end{array}$ & 0,76 & 1,01 & 1,54 & 1,41 & 1,82 \\
\hline $\begin{array}{c}0 \% \_30 \% \\
\text { Filler_aditive } \\
\end{array}$ & 1,55 & 2,60 & 3,98 & 4,84 & 6,39 \\
\hline \multirow{2}{*}{ AM $120 \mathrm{lpc}$} & \multicolumn{5}{|c|}{ Cyan Colour difference CIE LAB DE2000 } \\
\hline & $20 \%$ TV & $40 \% \mathrm{TV}$ & $60 \% \mathrm{TV}$ & $80 \% \mathrm{TV}$ & $100 \%$ TV \\
\hline $\begin{array}{c}0 \% \_10 \% \\
\text { Filler_aditive }\end{array}$ & 0,39 & 0,98 & 0,93 & 1,01 & 1,65 \\
\hline $\begin{array}{c}0 \% \_20 \% \\
\text { Filler_aditive }\end{array}$ & 1,25 & 1,36 & 1,36 & 1,60 & 1,85 \\
\hline $\begin{array}{c}0 \% \_30 \% \\
\text { Filler_aditive }\end{array}$ & 2,17 & 3,39 & 4,64 & 5,54 & 6,65 \\
\hline
\end{tabular}




\section{CONCLUSIONS}

With the FM screening, the addition of a filler in cyan ink will result in colour changes in which the brightness coordinate increases and the prints become brighter. By reducing the size of the screening dots, the brightness decreases, and the colour differences become lower.

By using the AM screenings and adding different concentrations of ink filler, more stable cyan prints are achieved. The colour difference is less pronounced than prints with the FM screenings. This will result in that cyan prints that are closer to the PSO reference values. By applying a larger line screening (120 AM screenings) colour deviation of cyan tones are larger and is not recommended for the realization of cyan tones.

Although the addition of fillers changes the rheological properties of ink (reduces the stickiness and possible tearing of the printing substrate), the optimal amount of filler additives should not exceed $10 \%$. A higher percentage of ink fillers lose the target solid tone reference value and thus the contrast of the prints.

These tests and results make more sense in security printing where more expensive printing inks (pigments) are used. Therefore, the following tests will be performed on printing inks that have a response outside the visible colour spectrum (UV and IR range).

\section{REFERENCES}

[1] Christie, R.M.: "Colour chemistry", (Royal Society of Chemistry United Kingdom, 2001.).

[2] Jamnicki, S.: Tiskarske boje, 2013a, URL: http://materijali.grf.unizg.hr/media/punila_cadje_bronce\%20[Compatibility \%20 Mode].pdf (last request: 2020-09-03.).

[3] Jamnicki, S.: Tiskarske boje 2013b, URL: http://materijali.grf.unizg.hr/media/susenje\%20TB\%20[Compatibility \%20Mode].pdf (last request: 2020-09-03.).

[4] Leach, R.H., Pierce, R.J.: "The Printing Ink Manual", (Springer, London, 1993.).

[5] Majnarić, I.: "The quality of digital prints caused by aging of printing substate", Msc thesis, University of Zagreb, 2004.

[6] Thompson, B.: "Printing materials: science and technology", (Pira International, Surrey, United Kingdom, 2004.).

[7] Turinski, Ž.: "Boje, veziva, tehnike slikanja”, (Biblioteka Zodijak, Beograd, 1970.).

[8] Vančina, V., Mikota, M.: "Materijali u grafičkoj proizvodnji”, (Grafički fakultetu Sveučilišta u Zagrebu, Zagreb, 1993.).

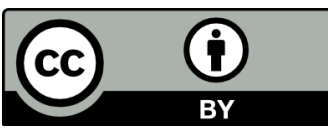

(C) 2020 Authors. Published by the University of Novi Sad, Faculty of Technical Sciences, Department of Graphic Engineering and Design. This article is an open access article distributed under the terms and conditions of the Creative Commons Attribution license 3.0 Serbia (http://creativecommons.org/licenses/by/3.0/rs/). 